\title{
BEßLICH, Barbara, Der deutsche Napoleon-Mythos. Literatur und Erinnerung, 1800-1945
}

\section{Karine Rance}

\section{OpenEdition}

\section{Journals}

Édition électronique

URL : http://journals.openedition.org/ifha/626

DOI : $10.4000 /$ ifha. 626

ISSN : 2198-8943

Éditeur

IFRA - Institut franco-allemand (sciences historiques et sociales)

Référence électronique

Karine Rance, «BEßLICH, Barbara, Der deutsche Napoleon-Mythos. Literatur und Erinnerung, 1800-1945 », Revue de I'IFHA [En ligne], Date de recension, mis en ligne le 01 janvier 2007, consulté le 22 septembre 2020. URL : http://journals.openedition.org/ifha/626 ; DOI : https://doi.org/10.4000/ifha.626

Ce document a été généré automatiquement le 22 septembre 2020

(CIFHA 


\title{
BEßLICH, Barbara, Der deutsche Napoleon-Mythos. Literatur und Erinnerung, 1800-1945
}

\author{
Karine Rance
}

Napoléon lieu de mémoire et mythe national allemand : la thèse d'habilitation en germanistique de B.B. présente une histoire littéraire du mythe de Napoléon qui complète la perspective que nous offraient les ouvrages de Natalie Petiteau (Napoléon de la mythologie à l'histoire, Paris : Seuil, 1999) et de Sudhir Hazareesingh (La légende de Napoléon, tr. fr. Paris : Tallandier, 2005). Elle propose en miroir l'image de Napoléon dans l'espace germanique en ne traitant pas d'historiographie ou d'objets-mémoire mais de littérature, ceci avec un souci permanent de contextualisation.

Reprenant les termes de Friedrich Sieburg (1956), l'auteur souligne que l'image de Napoléon pourrait avoir été plus déterminante dans l'imagerie nationale allemande que pour celle des Français ou des Britanniques. Le parallèle établi en Allemagne après 1945 avec l'ascension fulgurante napoléonienne a déjà largement été traité. Ce qui intéresse B.B. est l'évolution de l'image de Bonaparte qui, rappelle-t-elle, n'a été dessiné sous les traits de l'antéchrist qu'après avoir été pratiquement divinisé par ses partisans à partir de 1797.

Son objectif est de faire l'archéologie d'une mémoire culturelle qui transforme Napoléon « ennemi national » en mythe emblématique du caractère germanique. Pour cela B.B. emprunte des instruments d'analyse non seulement à la littérature, mais aussi aux sciences sociales et à l'histoire. S'interrogeant sur la valeur heuristique du mythe, elle y a associé les notions de lieu de mémoire et de modèle d'interprétation. Par mythe, B.B. entend une mythification du personnage historique (Wulf Wülfing) procèdant d'une concentration sur certains signes sémantiques (les mythèmes de Roland Barthes) qui esthétisent et « a-historisent » la figure historique.

Les textes qui ont été rassemblés sont ainsi considérés comme révélateurs du présent de l'Allemagne plus que du passé de Napoléon. Pris dans leur intertextualité, ils dessinent un autoportrait de la nation, renseignent sur le rapport à la grandeur 
historique, à l'attente messianique, au mythe de l'homme fort et du génie. La comparaison établie dès 1933 entre Hitler et Napoléon, souligne l'auteur, n'est donc guère surprenante.

Mais ces textes ne sont pas seulement l'expression de la société allemande à une période donnée : ils agissent aussi sur cette société comme producteurs de sens. B.B. est parfaitement convaincue de la puissance créatrice de la littérature et de la capacité de l'écrivain à fonder le mythe. Une telle histoire imaginée se situe au-delà de la falsification scientifique, elle vise à agir sur le présent et à influencer l'avenir. Enfin, la figure napoléonienne répondait à la question, que se posaient certains Allemands du XIXe s., de savoir si les hommes ou les peuples faisaient l'histoire, tant Napoléon semblait incarner les deux éléments.

L'ouvrage est conçu en trois parties : la première analyse la production littéraire contemporaine de Napoléon (1796-1821), particulièrement l'œuvre de Wieland et de Hölderlin, mais aussi celle de Kleist, Kotzebue, Heine, Goethe, Chamisso, etc. Dans un premier temps, ceux qui s'enthousiasment pour le stratège militaire le comparent à des héros tels que Alexandre le Grand, Hannibal, César, ou Charlemagne, reprenant en cela les modèles initiés par Bonaparte lui-même. En réponse, ses opposants invoquent des héros extra-européens comme Attila, ou des figures de l'antéchrist, particulièrement pendant les guerres de libération. De telles représentations ont été encouragées par la propagande anti-napoléonienne. Immédiatement après sa mort, c'est Napoléon luimême qui devient figure mythique et modèle à l'aune duquel on juge le présent.

La seconde période couvre le reste du XIXe s. (à partir des réflexions de Nietzsche notamment). Napoléon est pour les libéraux du Vormärz l'empereur du peuple, sous l'influence du mémorial de Las Casas. Il est le Génie auto-créé, le symbole d'une grandeur à laquelle on oppose la médiocrité du présent de la Restauration. Le mythe de Napoléon évolue avec un tournant particulièrement marqué lorsque la génération qui lui a été contemporaine disparaît pour céder la place à une génération d'écrivains n'ayant plus accès à une mémoire communicative (Jan Assmann). Après 1848, il n'est plus l'ennemi national de l'époque des guerres de libération mais une figure d'identification nationale. Cette tendance s'accentue après 1890, favorisée par le climat anglophobe de l'Allemagne wilhelmienne. Si bien qu'au moment de célébrer le centenaire des guerres de libération, en 1913, Napoléon n'apparaît que très rarement en tant qu'ennemi ou conquérant. Le contexte de la première Guerre mondiale favorise le parallèle qui est fait avec le combat de Napoléon contre les Anglais et le reste du monde. Il n'est donc pas réductible, après sa mort, selon l'auteur, à cette figure fondatrice du nationalisme allemand telle qu'elle apparaît dans la " patrie de l'ennemi " (Michael Jeissmann). Napoléon devient à cette période véritablement un lieu de mémoire allemand, comme il a été montré dans l'ouvrage d'Etienne François et Hagen Schulze (Mémoires allemandes, tr. fr. Paris : Gallimard, 2007). Cependant la littérature est le médium privilégié de cette mémoire : Napoléon, ancien adversaire militaire, est quasiment ignoré par la mémoire officielle; il n'apparaît ni dans les cérémonies ni sur les monuments.

La troisième partie est consacrée au premier XXe s., " ère du Napoléon allemand ». Bonaparte est totalement intégré à la mythologie nationale. Il n'est d'ailleurs plus présenté comme Français mais comme Corse, distingué de la nation qu'il dirigeait. L'Allemagne post-révolutionnaire de 1918 se compare avec la France de 1799 en attente d'un sauveur. Omniprésent sous la République de Weimar, Napoléon est invoqué à 
partir de 1933 pour appeler à la résistance contre le nazisme. "Toute littérature allemande sur Napoléon est, à partir de 1933, également une littérature sur Hitler ». Au lendemain de la guerre, Napoléon et son mythe sont jugés avoir eu une responsabilité dans le national-socialisme. Bonaparte est alors présenté comme le précurseur des dictatures modernes.

C'est donc finalement pendant la très courte période des guerres de libération que Napoléon a incarné l'ennemi national (surtout entre 1807 et 1815). B.B. souligne ainsi que le mythe napoléonien n'est pas uniquement le résultat de la volonté d'un homme. Il ne peut pas non plus être réduit au bonapartisme en tant qu'idéologie par rapport au XXe s. Le génie de Napoléon sert avant tout de définition esthétique de soi. Même dans le cas d'Heinrich Heine, dont l'ouvrage est plus engagé politiquement, on y apprend davantage politique. La littérature allemande du XIXe s. s'interroge certes sur la nature du pouvoir napoléonien, mais traite Napoléon d'une manière très peu politisée sur la relation de l'auteur au romantisme que sur ses positions politiques.

$\mathrm{Au}$ total, un livre très éclairant et passionnant. La limite aux yeux d'un historien (et on ne saurait en tenir grief à un ouvrage de germanistique) tient au traitement purement littéraire de la question. Mais le souci de contextualisation est tel que l'ouvrage est parfaitement utile dans une optique historienne.

Karine RANCE (Université Blaise-Pascal - Clermont-Ferrand II) 